\title{
Article
}

\section{The Importance of Intraoperative Plain Radiographs during Cochlear Implant Surgery in Patients with Normal Anatomy}

\author{
Ohad Cohen ${ }^{1,2} \oplus$, Jean-Yves Sichel ${ }^{1,2}$, Chanan Shaul ${ }^{1,2}$, Itay Chen ${ }^{1,2}, \mathrm{~J}_{\text {. Thomas Roland, Jr. }}{ }^{3}$ and \\ Ronen Perez $1,2, *$ (D) \\ 1 Faculty of Medicine, Hebrew University of Jerusalem, Jerusalem 9112102, Israel; ohad.c4@gmail.com (O.C.); \\ Sicheljy@szmc.org.il (J.-Y.S.); hananshaul@gmail.com (C.S.); chenitay2@gmail.com (I.C.) \\ 2 Department of Otolaryngology-Head and Neck Surgery, Shaare Zedek Medical Center, Jerusalem 9103102, Israel \\ 3 Department of Otolaryngology-Head \& Neck Surgery, NYU School of Medicine, New York, NY 10016, USA; \\ J.Thomas.RolandJr@nyulangone.org \\ * Correspondence: perezro@inter.net.il; Tel.: +972-2-666-6367
}

Citation: Cohen, O.; Sichel, J.-Y.; Shaul, C.; Chen, I.; Roland, J.T., Jr.; Perez, R. The Importance of Intraoperative Plain Radiographs during Cochlear Implant Surgery in Patients with Normal Anatomy. Appl. Sci. 2021, 11, 4144. https://doi.org/ 10.3390/app11094144

Academic Editor: Luca Testarelli

Received: 2 April 2021

Accepted: 29 April 2021

Published: 30 April 2021

Publisher's Note: MDPI stays neutral with regard to jurisdictional claims in published maps and institutional affiliations.

Copyright: (C) 2021 by the authors. Licensee MDPI, Basel, Switzerland. This article is an open access article distributed under the terms and conditions of the Creative Commons Attribution (CC BY) license (https:/ / creativecommons.org/licenses/by/ $4.0 /)$.

\begin{abstract}
Although malpositioning of the cochlear implant (CI) electrode array is rare in patients with normal anatomy, when occurring it may result in reduced hearing outcome. In addition to intraoperative electrophysiologic tests, imaging is an important modality to assess correct electrode array placement. The purpose of this report was to assess the incidence and describe cases in which intraoperative plain radiographs detected a malpositioned array. Intraoperative anti-Stenver's view plain X-rays are conducted routinely in all CI surgeries in our tertiary center before awakening the patient and breaking the sterile field. Data of patients undergoing 399 CI surgeries were retrospectively analyzed. A total of 355 had normal inner ear and temporal bone anatomy. Patients with intra or extracochlear malpositioned electrode arrays demonstrated in the intraoperative X-ray were described. There were four cases of electrode array malposition out of 355 implantations with normal anatomy (1.1\%): two tip fold-overs, one extracochlear placement and one partial insertion. All electrodes were reinserted immediately; repeated radiographs were normal and the patients achieved good hearing function. Intraoperative plain anti-Stenver's view X-rays are valuable to confirm electrode array location, allowing correction before the conclusion of surgery. These radiographs are cheaper, faster, and emit much less radiation than other imaging options, making them a viable cost-effective tool in patients with normal anatomy.
\end{abstract}

Keywords: intraoperative plain X-ray; anti-Stenver's view; cochlear implantation; electrode array malposition; tip fold-over

\section{Introduction}

The objective of cochlear implant surgery is complete insertion of the electrode array into the cochlear scala tympani [1]. Although intra and extracochlear malposition of the electrode array is rare in patients with normal inner ear and temporal bone anatomy, when it occurs it may lead to reduced hearing outcomes. Therefore, the correct placement of the electrode array is crucial to achieve maximal postoperative auditory function [2-4]. Moreover, the incidence of tip fold-over is reported to be about $2 \%$, in some electrodes, affecting implant and patient performance [5]. In addition to intraoperative electrophysiologic tests, imaging is an important modality to assess the correct placement of the electrode array. Intraoperative diagnosis of an abnormal electrode position before awakening the patient has a significant advantage over identifying malposition postoperatively. It enables real time correct positioning and therefore spares the patient and the health care system the burden of revision surgery or suboptimal implant performance. Telling a parent that it will be necessary to take a child back to the operating theatre to fix a problem that occurred during surgery is a very uncomfortable conversation, and these cases have led to distrust of a surgeon or center as well as medical malpractice litigation. An intraoperative plain 
anti-Stenver's (cochlear) view radiograph offers a quick, cheap method to diagnose and reinsert a displaced electrode array before the termination of anesthesia. Other methods to evaluate the array position are intra and postoperative computed tomography (CT), cone beam CT or fluoroscopy. In comparison to plain radiographs, those methods are more expensive and time consuming [6]. Moreover, they carry higher exposure to radiation for the patient and personnel in the operating room. Nevertheless, in patients with anatomic malformations, fluoroscopy has an important role [7-9].

The purpose of this report was to assess the incidence and describe cases with normal anatomy in which electrode misplacement was diagnosed by intraoperative plain radiographs and corrected before the termination of anesthesia, demonstrating the efficacy of this tool.

\section{Materials and Methods}

\subsection{Patients}

Surgical reports, imaging and results of intraoperative electrophysiological test data were retrospectively analyzed for 399 cochlear implantations performed in Shaare Zedek Medical Center; 355 were with normal anatomy and 44 with anatomical malformations as assessed by preoperative $\mathrm{CT}$, magnetic resonance imaging (MRI), or both. In our center, we perform a routine intraoperative anti-Stenver's cochlear view plain X-ray in every single implantation after flap closure and before breaking the sterile field and termination of anesthesia. Patients with an intra or extracochlear malpositioned electrode array demonstrated in the intraoperative X-ray were retrieved. Collected data for these cases included: patient characteristics, surgical reports, implant and electrode type, use of intraoperative electrophysiological tests, results of intraoperative imaging and auditory outcome.

\subsection{Imaging Technique}

A routine intraoperative imaging in the anti-Stenver's "cochlear view" [10] (Figure 1) was obtained in all surgeries following the electrode array insertion, cochleostomy and flap closure. A mobile X-ray machine handled by a radiography technician was used. The head was rotated approximately $25-30$ degrees to the contralateral side. The machine was covered with a sterile sheet to prevent inadvertent contamination. The image was immediately presented on the machine's screen and evaluated by the surgeons for the position and contour of the electrode. In addition to the electrode array position, the inner ear including the vestibule semicircular canals and cochlea could be seen in the plain radiograph. The $\mathrm{X}$-ray was subsequently uploaded to the picture archiving and communication system (PACS) for future analysis and documentation. The overall time to imaging and evaluation of the position did not exceed 2-3 min. For bilateral implantation, each side was imaged separately with the same technique. Alternatively, one A-P view X-ray can be performed to evaluate both sides.

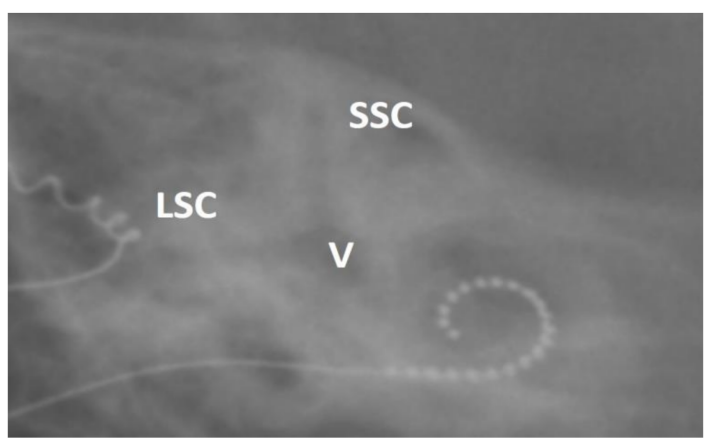

Figure 1. Plain anti-Stenver's radiograph in the "cochlear view". Correct spiral curve of the array is seen within the cochlea. SCC: superior semicircular canal, LSC: lateral semicircular canal, V: vestibule. 
The study was approved by the Shaare Zedek Medical Center Institutional Helsinki Committee (approval number 0257-20 SZMC).

\section{Results}

Intraoperative radiographs detected four misplaced CI electrode arrays out of 355 ears with normal anatomy $(1.1 \%)$ implanted in our center. A summary of their characteristics is presented in Table 1. All four had preoperative CT or MRI demonstrating normal temporal bone anatomy.

Table 1. Characteristics of cochlear implant patients with misplaced electrode arrays on intraoperative radiographs.

\begin{tabular}{|c|c|c|c|c|c|c|c|}
\hline $\begin{array}{l}\text { Patient } \\
\text { No. }\end{array}$ & $\begin{array}{c}\text { Age at } \\
\text { Implantation }\end{array}$ & Indication & Implant & NRT/NRI & $\begin{array}{c}\text { Intraoperative } \\
\text { Radiograph }\end{array}$ & $\begin{array}{l}\text { Post Reinsertion } \\
\text { Radiographs }\end{array}$ & $\begin{array}{c}\text { Post Reinsertion } \\
\text { NRT/NRI }\end{array}$ \\
\hline 1 & 2 years & Congenital HL & Cochlear CI512 & Normal & Tip fold-over & Normal & Normal \\
\hline 2 & 11 months & $\begin{array}{l}21 \text { trisomy } \\
\text { Idiopathic, } \\
\text { congenital HL }\end{array}$ & $\begin{array}{l}\text { Ab hr90k/ } \\
\text { Hi-Focus } 1 j\end{array}$ & $\begin{array}{l}\text { No response at } \\
\text { basal electrode }\end{array}$ & $\begin{array}{l}\text { Incomplete } \\
\text { insertion }\end{array}$ & Normal & $\begin{array}{l}\text { Normal, } \\
\text { including basal } \\
\text { electrodes }\end{array}$ \\
\hline 3 & 22 years & $\begin{array}{c}\text { Prematurity } \\
\text { Congenital } \\
\text { progressive HL }\end{array}$ & $\begin{array}{l}\text { AB HR90K/ } \\
\text { Hi-Focus MS }\end{array}$ & No response & $\begin{array}{l}\text { Oval curve, } \\
\text { acute-angled }\end{array}$ & Normal & No response \\
\hline 4 & 4 years & $\begin{array}{c}\text { Familial } \\
\text { progressive HL }\end{array}$ & Cochlear CI632 & Normal & Tip fold-over & Normal & Normal \\
\hline
\end{tabular}

HL: hearing loss, AB: Advanced Bionics, NRT: neural response telemetry (Cochlear Ltd.), NRI: neural response imaging (Advance Bionics Ltd.).

\subsection{Case 1: Tip Fold-Over}

Two-year-old male with progressive congenital bilateral sensorineural hearing loss (SNHL). The insertion of a cochlear device (CI512) was uneventful and impedance and neural responses (NRT) were normal from all electrodes. However, the intraoperative radiograph revealed fold-over of the array's tip (Figure 2). Of note, although not routinely used in our center, spread of excitation (SOE) measurement was conducted in this case, demonstrating a biphasic pattern which is characteristic of tip fold-over [11]. Following the extraction of the array, re-insertion was smooth and repeat imaging showed the array in the correct position. Post reinsertion impedance, NRT and SOE were normal.

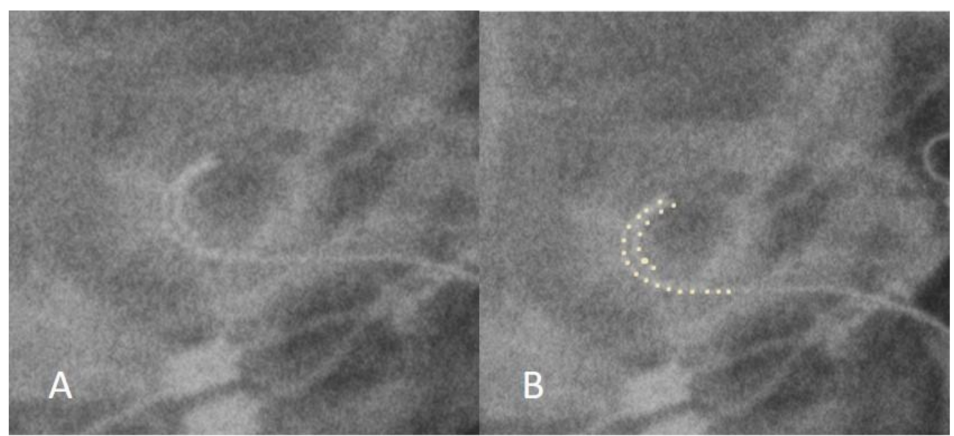

Figure 2. Case 1, tip fold-over. (A) - Original, (B)_Electrodes are highlighted for demonstration.

\subsection{Case 2: Incomplete Insertion}

Eleven-month-old male with 21 trisomy and bilateral congenital SNHL. The insertion of the Advanced Bionics (HR90k/Hi-Focus-1j) electrode array was smooth and complete. Impedance was within normal limits in all electrodes. Normal NRI was obtained from apical electrodes, but there were no responses from basal electrodes. The intraoperative radiograph showed a partially inserted electrode (Figure 3). We believe the electrode array was fully inserted but then partially migrated out during the closure of the flaps. The flaps were re-opened and the array was gently pushed in and secured. Post re-insertion imaging, impedance and NRI were normal. 


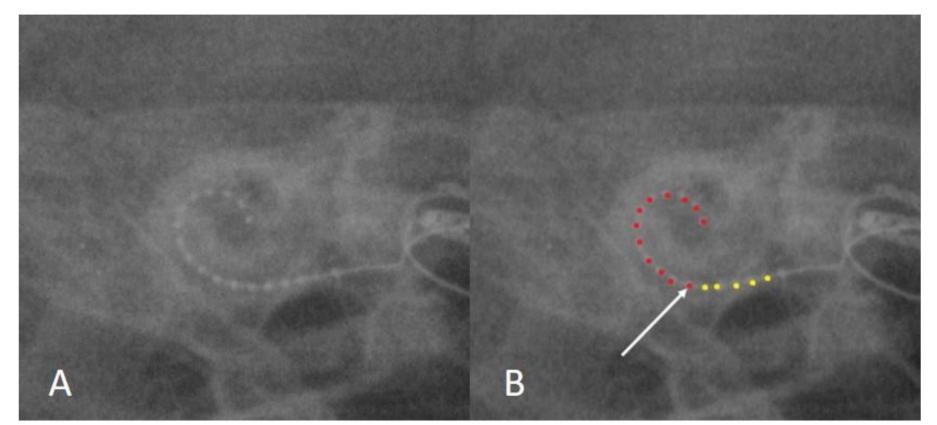

Figure 3. Case 2, partial insertion. (A)—Original, (B)_Arrow pointing at the location of cochleostomy. Basal electrodes are marked in yellow, located out of the cochlear cavity. Intracochlear electrodes are marked in red, forming an incomplete spiral curve.

\subsection{Case 3: Extracochlear Electrode Array Malposition}

Twenty-two-year-old male with progressive bilateral congenital SNHL. The patient successfully used bilateral hearing aids but in the years before implantation had limited benefit from the amplification. The surgical report noted that the round window could not be visualized by the surgeons through the narrow facial recess that could be achieved in this case without jeopardizing the facial nerve. The round window was probably posterior to the visual field through the narrow facial recess. Nevertheless, drilling a "cochleostomy" exposed a cavity compatible with intracochlear scala and the electrode array was smoothly inserted (Advanced Bionics HR90K/Hi-Focus-MS). NRI showed no response. Impedance levels were high and identical across all electrodes. Radiography failed to demonstrate the desired spiral curve but rather an amorphic shape with an acute angle at the apical end of the array (Figure 4). Extracochlear (hypotympanic cells) misplacement was assumed and therefore the electrode was removed and reinserted after a superior enlargement of the cochleostomy. The repeat imaging showed a normal spiral curve, yet no responses on NRI were seen. Impedance was within normal limits in all electrodes. On postoperative implant mapping, NRI was normal and the patient achieved the expected audiologic goals.

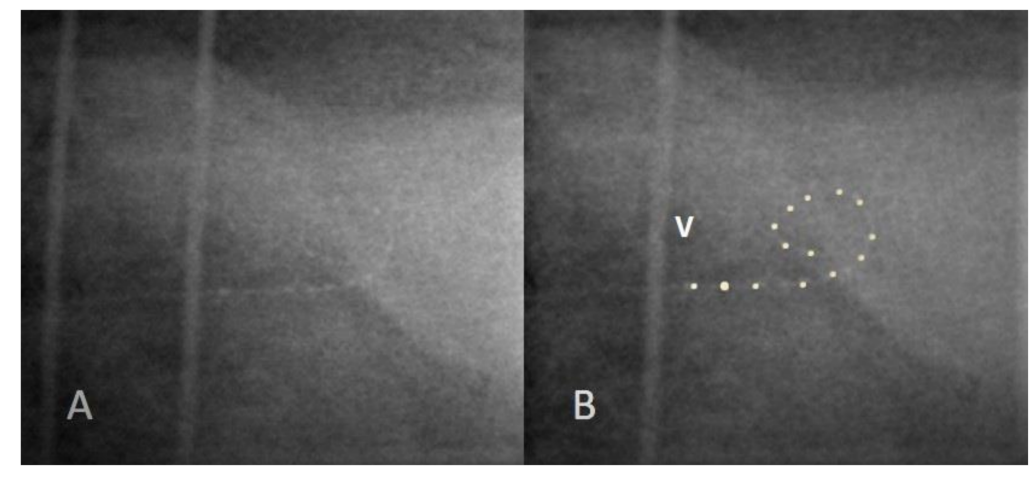

Figure 4. Case 3, extracochlear misplacement. Oval appearance and acute angle at the apical end. (A) — Original, (B) -Electrodes are highlighted for demonstration. V: vestibule.

\subsection{Case 4: Distal Tip Fold-Over}

Four-year-old male with progressive genetic SNHL underwent uneventful cochlear implantation. The electrode array of the cochlear device (CI632) was completely and smoothly inserted. Normal impedance and NRT were obtained from all electrodes; however, the intraoperative X-ray showed a distal tip fold-over (Figure 5). The array was removed, reloaded and inserted again. Post re-insertion imaging, impedance and NRT were normal. 


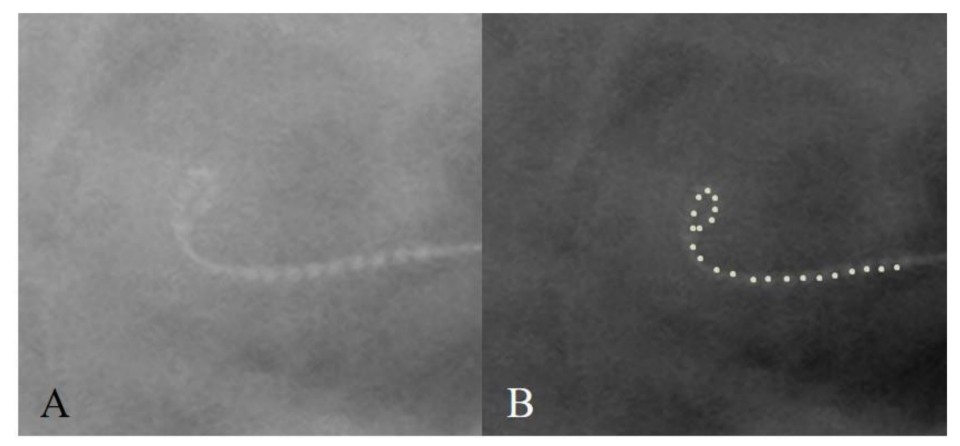

Figure 5. Case 4, tip fold-over. (A)—Original, (B)—Electrodes are highlighted for demonstration.

\section{Discussion}

This study reports four cases of cochlear implant electrode array misplacement out of $355 \mathrm{CI}$ procedures conducted in ears with normal anatomy. The malposition was diagnosed by the intraoperative plain radiographs, allowing reinsertion before terminating anesthesia.

The objective of cochlear implantation surgery is complete insertion of the electrode array into the scala tympani with minimal trauma to cochlear partitions or nearby structures. Correct positioning of the electrode correlates with better audiologic function for the patient [12,13]. Overall, the reported incidence of electrode malposition (tip fold-over, extracochlear insertion, kinking, incomplete insertion) is $<1 \%-5 \%[14,15]$ including cases with normal anatomy. Specifically, a tip fold-over incidence of $1.57 \%$ was found in a review of 13 articles, predominantly in the pre-curved cochlear implants [16]. The array misplacement incidence in our cohort of patients with normal anatomy was $1.1 \%$ with a tip fold-over incidence of $0.6 \%$, corresponding with the published literature.

The main purpose of intraoperative plain radiographs in cochlear implant surgery is to answer the question-is the electrode array correctly positioned inside the cochlea? The advantage of performing routine images in every surgery over selective imaging is demonstrated in a study which retrospectively compared intraoperative radiograph findings to the surgeon's impression of resistance during insertion as documented in the surgical report. It was found that the surgeon's suspicion of misplacement had only a $29 \%$ positive predictive value. Thus, if imaging had not been used for uneventful insertions, nearly half of the misplaced implants would have been overlooked [10]. When applying this to the four patients presented in this report, in cases 1, 2 and 4 (fold-overs and incomplete insertion) no abnormality or resistance during insertion was noticed, and only the performance of the routine intraoperative X-ray prevented misplacement. As for case 3, although some anatomic variation was noticed intraoperatively, the cochleostomy and insertion were uneventful and, again, if intraoperative radiographs had not been routinely used, chances are that imaging would not have been specially requested and the extracochlear position would have been missed. Case 3 also demonstrates a potential pitfall in pre-curved arrays regarding intraoperative imaging. Once the stylet is removed, the pre-curved array coils into a spiral form even though it is positioned out of the cochlea [17]. As seen in Figure 3, the array actually curved to some degree despite not being in the cochlea, and a high index of suspicion was needed in order to detect the oval curvature and the acute-angle in the apex. The electrode was also not medial to the vestibule, which indicated a hypotympanic placement.

Neural response and impedance are standard intraoperative electrophysiological tests for monitoring the electrode array integrity and the patient's response to stimuli from the implant. In a comparison between NR, impedance and plain radiographs in 277 patients with normal cochlear anatomy, Cosetti et al. [15] showed that radiographs were superior to NR and impedance and concluded that only radiographs may be used independently in the decision to remove a misplaced array intraoperatively. In a study by Zuniga et al. [18], six patients with tip fold-overs demonstrated by imaging were reviewed. Impedance and NR were normal in all six, demonstrating their low predictive value for misplacement. In 
this report, other electrophysiological tests (electrical field imaging and SOE) were abnormal. However, those tests were conducted postoperatively; therefore, the implants were not replaced and the deactivation of some electrodes was needed. Grolman et al. [11] compared intraoperative SOE testing to imaging (3-D rotational X-ray) in 72 ears for the diagnosis of tip fold-over. SOE was found to be an accurate diagnostic tool for tip fold-over, detecting all four cases (5.5\% incidence). Nevertheless, imaging may be superior to SOE testing for two reasons: firstly, SOE testing requires an in-depth knowledge of the different manufacturers' software and is performed by an expert audiologist; secondly, imaging is diagnostic for a variety of misplacements other than fold-over. In our report, the two patients with tip fold-over had normal NR and impedance. The patient in case 1 was one of the first patients nationally implanted with the CI512 device and SOE testing was conducted for academic purposes. Nevertheless, the abnormality was seen in the radiograph, and reinsertion would have been performed regardless of the SOE results.

For extracochlear misplacements, NR may be more sensitive, although for intralabyrinth-extracochlear locations (vestibular labyrinth), normal responses may be found $[5,19]$. Case 3 further illustrates the limitation of electrophysiologic testing. Even after the successful full intracochlear reinsertion, no responses were measured. Upon switch-on and in further mapping sessions, neural responses were obtained from all electrodes. In our experience, it is not uncommon to receive partial responses or even no responses intraoperatively but then have complete neural responses later at the time of switching on the device.

In contrast to the two-dimensional image in plain radiographs, computed tomography provides three-dimensional information of the temporal bone and cochlear implant electrode position, and is mainly used worldwide for pre- and postoperative imaging. Mostly the high-resolution CT (HRCT) or the less radiating cone beam CT (CBCT) is used. The utility of intraoperative CT was illustrated in some reports in cases of inner ear malformations $[3,20]$; however, we believe it has no clear advantage in ears with normal anatomy. As mentioned, the inner ear anatomy including the vestibular part can be seen in the plain radiographs.

Two disadvantages of $\mathrm{CT}$ are higher radiation exposure and cost. The radiation doses of $\mathrm{CT}$ are much higher than those of plain radiographs, regardless of the type of system being used. The exposure dose for high resolution CT is approximately $1000 \mu \mathrm{Sv}$, while doses of cone beam CT are about $50 \mu \mathrm{Sv}$ [21]. When compared to doses of around $2 \mu \mathrm{Sv}$ of a plain radiograph, the difference is significant, especially in the pediatric population which are anticipated to undergo re-implantations in the future and possible additional imaging for other reasons. In addition, prepping and scanning the patient takes about $8 \mathrm{~min}$ as estimated in one study, and the overall cost of use of CT per surgery was USD $721[6]$.

When specifically addressing the cone beam CT, it should be noted that it is superior to the plain X-ray in the accuracy it can provide regarding the location of the electrode array. In contrast to the plain X-ray, the cone beam CT can determine if the electrode array is in the scala tympani or scala vestibuli. Nevertheless, the plain X-ray is still much easier to perform intraoperatively, and it is cheaper, quicker and emits less radiation. Importantly, the intraoperative cone beam CT is not available in many centers that perform CI, and therefore we believe the plain traditional X-ray is still a good and viable option for detecting the misplacement of the electrode array.

This review presents four examples in which abnormal electrode position was detected intraoperatively by the use of plain radiographs and was successfully repositioned. The routine usage of intraoperative radiographs in $100 \%$ of cochlear implant patients with normal anatomy further validates this report by avoiding sampling bias.

The three patients (two with tip fold-overs and one with incomplete insertion) would have probably gained benefit from their misplaced implant to some degree in terms of hearing and communication. Most probably after months or years, less then optimal func- 
tion would warrant investigation. Performing the intraoperative imaging and correcting the misplacement allowed the achievement of maximal potential results from the start.

In our center, as a result of the routinely performed intraoperative X-ray, all $399 \mathrm{CI}$ procedures resulted in correct and optimal placement of the electrode array, and it is nice to speak to the family after surgery with full confidence that the electrode array is in place. We did have one case in which slow migration of the array occurred in the months after surgery. In this case, the normal intraoperative radiograph was useful in the knowledge that the migration occurred in the post-surgical period.

Therefore, we carefully recommend considering the use of plain radiographs routinely during cochlear implant surgeries in patient with normal temporal bone anatomy.

\section{Conclusions}

Intraoperative plain anti-Stenver's view radiographs offer a valuable option for the surgeon to confirm the electrode array position, and more importantly, allow the opportunity to correct a misplaced array before the termination of anesthesia. Plain X-rays are cheaper, faster and emit much less radiation than alternative options and are therefore are a viable cost-effective tool in patients with normal anatomy.

Author Contributions: Conceptualization, O.C., J.-Y.S., C.S., I.C., J.T.R.J. and R.P.; methodology, O.C., J.-Y.S. and R.P.; formal analysis, O.C., C.S., I.C. and J.T.R.J. and R.P.; writing-original draft preparation, O.C. and R.P.; writing—review and editing, O.C., J.-Y.S., C.S., I.C., J.T.R.J. and R.P.; supervision, J.-Y.S., J.T.R.J. and R.P. All authors have read and agreed to the published version of the manuscript.

Funding: This research received no external funding.

Institutional Review Board Statement: The study was conducted according to the guidelines of the Declaration of Helsinki, and approved by the Institutional Review Board (or Ethics Committee) of Shaare Zedek Medical Center (approval 0257-20-SZMC on 28 June 2020).

Informed Consent Statement: Patient consent was waived by the Institutional Review Board (Ethics Committee) because the study was retrospective, based on non-identifying data taken from the patients' medical records.

Conflicts of Interest: Dr JT Roland is a consultant and recipient of research support from Cochlear Americas. The other authors do not have any conflicts of interest to disclose.

\section{References}

1. Shaul, C.; Roland, J.T., Jr.; Sichel, J.Y.; Salem, R.; Perez, R. Revision cochlear implantation using a double array device in the post-meningitis ossified cochlea. Int. J. Pediatr. Otolaryngol. 2020, 139, 110446. [CrossRef] [PubMed]

2. Zaltz, Y.; Bugannim, Y.; Zechoval, D.; Kishon-Rabin, L.; Perez, R. Listening in Noise Remains a Significant Challenge for Cochlear Implant Users: Evidence from Early Deafened and Those with Progressive Hearing Loss Compared to Peers with Normal Hearing. J. Clin. Med. 2020, 9, 1381. [CrossRef] [PubMed]

3. Kim, C.S.; Maxfield, A.Z.; Foyt, D.; Rapoport, R.J. Utility of intraoperative computed tomography for cochlear implantation in patients with difficult anatomy. Cochlear Implant. Int. 2018, 19, 170-179. [CrossRef] [PubMed]

4. O'Connell, B.P.; Cakir, A.; Hunter, J.B.; Francis, D.O.; Noble, J.H.; Labadie, R.F.; Zuniga, G.; Dawant, B.M.; Rivas, A.; Wanna, G.B. Electrode location and angular insertion depth are predictors of audiologic outcomes in cochlear implantation. Otol. Neurotol. 2016, 37, 1016-1023. [CrossRef] [PubMed]

5. Ying, Y.L.M.; Lin, J.W.; Oghalai, J.S.; Williamson, R.A. Cochlear implant electrode misplacement: Incidence, evaluation, and management. Laryngoscope 2013, 123, 757-766. [CrossRef] [PubMed]

6. Labadie, R.F.; Schefano, A.D.; Holder, J.T.; Dwyer, R.T.; Rivas, A.; O'Malley, M.R.; Noble, J.H.; Dawant, B.M. Use of intraoperative CT scanning for quality control assessment of cochlear implant electrode array placement. Acta. Otolaryngol. 2020, 140, $206-211$. [CrossRef] [PubMed]

7. Fishman, A.J.; Roland, J.T.; Alexiades, G.; Mierzwinski, J.; Cohen, N.L. Fluoroscopically assisted cochlear implantation. Otol. Neurotol. 2003, 24, 882-886. [CrossRef] [PubMed]

8. Cosetti, M.K.; Friedmann, D.R.; Heman-Ackah, S.E.; Perez, R.; Waltzman, S.B.; Roland, J.T., Jr. Surgical techniques and outcomes of cochlear implantation in patients with radiographic findings consistent with X-linked deafness. Int. J. Pediatr. Otolaryngol. 2015, 79, 1689-1693. [CrossRef] [PubMed] 
9. Perez, R.; Salem, R.; Roland, J.T., Jr.; Sichel, J.Y. Fluoroscopic assisted cochlear implantation in children with inner ear malformations. Harefuah 2014, 153, 713-717. [PubMed]

10. Xu, J.; Xu, S.A.; Cohen, L.T.; Clark, G.M. Cochlear view: Postoperative radiography for cochlear implantation. Otol. Neurotol. 2000, 21, 49-56.

11. Grolman, W.; Maat, A.; Verdam, F.; Simis, Y.; Carelsen, B.; Freling, N.; Tange, R.A. Spread of excitation measurements for the detection of electrode array foldovers: A prospective study comparing 3-dimensional rotational x-ray and intraoperative spread of excitation measurements. Otol. Neurotol. 2009, 30, 27-33. [CrossRef] [PubMed]

12. Finley, C.C.; Skinner, M.W. Role of electrode placement as a contributor to variability in cochlear implant outcomes. Otol. Neurotol. 2008, 29, 920-928. [CrossRef] [PubMed]

13. Perez, R.; Kishon-Rabin, L. Cochlear implants-pediatric. In Encyclopedia of Otolaryngology, Head and Neck Surgery; Kountakis, S.E., Ed.; Springer: Berlin/Heidelberg, Germany, 2013.

14. Dirr, F.; Hempel, J.M.; Krause, E.; Müller, J.; Berghaus, A.; Ertl-Wagner, B.; Braun, T. Value of routine plain x-ray position checks after cochlear implantation. Otol. Neurotol. 2013, 34, 1666-1669. [CrossRef] [PubMed]

15. Cosetti, M.K.; Troob, S.H.; Latzman, J.M.; Shapiro, W.H.; Roland, J.T., Jr.; Waltzman, S.B. An evidence-based algorithm for intraoperative monitoring during cochlear implantation. Otol. Neurotol. 2012, 33, 169-176. [CrossRef] [PubMed]

16. Dhanasingh, A.; Jolly, C. Review on cochlear implant electrode array tip fold-over and scalar deviation. J. Otol. 2019, 14, 94-100. [CrossRef] [PubMed]

17. Sorrentino, T.; Côté, M.; Eter, E.; Laborde, M.L.; Cochard, N.; Deguine, O.; Fraysse, B. Cochlear reimplantations: Technical and surgical failures. Acta. Otolaryngol. 2009, 129, 380-384. [CrossRef] [PubMed]

18. Zuniga, M.G.; Rivas, A.; Hedley-Williams, A.; Gifford, R.H.; Dwyer, R.; Dawant, B.M.; Sunderhaus, L.W.; Hovis, K.L.; Wanna, G.B.; Noble, J.H.; et al. Tip fold-over in cochlear implantation: Case series. Otol. Neurotol. 2017, 38, 199-206. [CrossRef] [PubMed]

19. Hassan, A.M.; Patel, R.; Redleaf, M. Intra-operative skull X-ray for misdirection of the cochlear implant array into the vestibular labyrinth. J. Laryngol. Otol. 2015, 129, 923-927. [CrossRef] [PubMed]

20. Bloom, J.D.; Rizzi, M.D.; Germiller, J.A. Real-time intraoperative computed tomography to assist cochlear implant placement in the malformed inner ear. Otol. Neurotol. 2009, 30, 23-26. [CrossRef] [PubMed]

21. Saeed, S.R.; Selvadurai, D.; Beale, T.; Biggs, N.; Murray, B.; Gibson, P.; Risi, F.; Boyd, P. The use of cone-beam computed tomography to determine cochlear implant electrode position in human temporal bones. Otol. Neurotol. 2014, 35, 1338-1344. [CrossRef] [PubMed] 